\title{
Occupational health hazards and use of personal protective equipment among auto mechanics in Kathmandu Metropolitan City, Nepal
}

\author{
Khadka Rabina', Pandey Indira ${ }^{2}$, Gautam L ${ }^{1}$
}

${ }^{1}$ Lecturer, Department of Public Health, Manmohan Memorial Institute of Health Sciences, Kathmandu, Nepal, ${ }^{2}$ Health Promotion Officer, Janahit Grahmin Sewa Samittee, Sindhupalchowk, Nepal

\section{ABSTRACT}

Introduction: Auto mechanics are workers who repair and overhaul cars and other automotive vehicles, or their systems and parts. The main objective of the study was to assess knowledge of occupational hazards and the use of safety measures among automobile repair artisans in Kathmandu Metropolitan City.

Methods: A cross-sectional study was carried among 400 auto mechanics working garages in Kathmandu Metropolitan City. The data collection was done from May $15^{\text {th }}$ to Jun $13^{\text {th }}, 2019$.

Results: Among the 400 respondents, only $31 \%$ had adequate knowledge about occupational hazards due to vehicle repairing. Age, educational status, working hours, years of employment and pre-service training were found to be associated with knowledge on hazards. Two-thirds (63.5\%) of the surveyed workers knew the use of PPE and this knowledge was statistically significant with age, educational status, working hours and pre-service training. The study showed that only half $(53.5 \%)$ of the respondents use one or more PPE during their work despite being exposed to lots of hazards in the working area.

Conclusion: Knowledge on health hazards was inadequate. Also, there was a difference in knowledge on PPE and its use. So, there is a need to put the knowledge into practice.

Key words: Auto mechanics, Health hazards, Personal protective equipment.

\section{Introduction}

A ccording to International Labour Organization (ILO), occupational safety and health (OSH) is defined as the science of the anticipation, recognition, evaluation and control of hazards arising in or from the workplace that could impair the health and well-being of workers, taking into account the possible impact on the surrounding communities and the general environment. ${ }^{1}$

The ILO estimates that worldwide there are around 340 million occupational accidents and 160 million

DOI: https://doi.org/10.3126/ijosh.v11i1.33495

Date of submission: 17.12 .2020

Date of acceptance: 30.03 .2021

Corresponding Author
Rabina Khadka MPH
Lecturer,
Department of Public Health,
Manmohan Memorial Institute of Health Sciences,
Tribhuvan University, Kathmandu, Nepal
Email: khadkarabina17@gmail.com
ORCID ID - https://orcid.org/0000-0002-4593-9885

victims of work-related illnesses annually. ${ }^{2}$ In Nepal, it is estimated that each year approximately 20,000 workers suffer from accidents at the workplace, which lead to about 200 lives lost. ${ }^{2}$ There are various hazards in the occupational environment to which mechanics may be exposed, like work-related injuries, chronic illness, stress and, disability because of their low literacy rates, following unsafe practices, unfamiliarity with work process and exposures, and inadequate training. ${ }^{3}$

Personal protective equipment (PPE) is equipment such as gloves, shoes, helmets, respirators, eye protection, protective hearing devices (earplugs, muffs), and full bodysuits that is worn by the workers to minimize exposure to a variety of hazards. ${ }^{4}$

Health and safety is a low priority for workers because the urgency of earning a living takes priority over other concerns, there is a lack of awareness of the

\section{(c) (1) (8)}

This journal is licensed under a Creative Commons AttributionNon Commercial 4.0 International License. 
links between work and health, and there is a lack of understanding of the negative impact of poor health on productivity. ${ }^{5}$

Occupational hazard contributes to severe health problem among worker due to unhealthy condition and lack of safety. Nearly half of the workers (44.3\%) were using personal protective equipment, which indicates low PPE use and awareness on the occupational hazard in Kathmandu metropolitan city. ${ }^{6}$

It is important to use safety measures to prevent or reduce a variety of health hazards. Safety at the workplace is not just an important factor for promoting health of a worker but also an essential component of the efficiency and productivity of a country. ${ }^{5}$ This study was conducted to assess the knowledge on occupational health hazards and use of personal protective equipment among automobile mechanics.

\section{Methods}

A cross-sectional study was carried out among auto mechanics working in different garages in Kathmandu Metropolitan City. The list of garages in Kathmandu Metropolitan City was received from the Nepal Auto mechanics Trade Union Office in Kathmandu. The sample size was calculated by using the formula with $56 \%$ prevalence and $95 \%$ confidence interval. ${ }^{6}$ The actual sample size calculated was 400 with $10 \%$ nonresponse rate. All the automobile mechanics present in the workshop at the time of data collection were included in the study after receiving informed consent.

From the list provided, garages were randomly selected by using the lottery method. The data collection was done from May $15^{\text {th }}$ to Jun $13^{\text {th }}, 2019$. A semistructured questionnaire and observation checklist were used for data collection by using interview and observation technique. Pre-testing was done in Lalitpur Metropolitan City among the 10\% mechanics of the total sample having similar characteristics and required modification was done in close coordination with experts while doing sufficient literature review. Data were reviewed for completeness and consistency immediately after data collection. Data were cleaned, coded and classified as well and was entered manually in the computer using SPSS Version 20. Descriptive and Inferential analysis were done. Frequency, percentage, mean, standard deviation were calculated for univariate analysis and the association of different independent variables with dependent variables were determined by cross-tabulation, chi-square tests and binary logistic regression using computer software for bivariate analysis. The knowledge level was categorized as inadequate and adequate by the mean score of the knowledge obtained, those who had scored more than the mean score were considered as having adequate knowledge. Ethical approval was taken from the Institutional Review Committee (IRC) of Manmohan Memorial Institute of Health Science (MMIHS). Permission for the data collection was taken from the president of the Nepal Auto Mechanics Trade Union. The participants were informed about the aims, methods and anticipated benefits of the study program and informed consent was taken from all respondents while maintaining confidentiality and privacy. Automechanics who were absent on the day of data collection were excluded from the study. Regarding the limitation of this study, the list taken for the sampling frame was not updated recently which could have missed the respondents from new workshops.

\section{Results}

A total of 400 automobile mechanics of Kathmandu Metropolitan City were studied to determine the knowledge of occupational health hazards and use of personal protective equipment and factors associated with them. More than one-third (35.8\%) of the respondents were from the age group 20-30 years. There were 398 male and two female mechanics. Most of the respondents $(76.5 \%)$ were Hindu and more than one-third $(34.8 \%)$ were from the Janajati group. More than half $(56.5 \%)$ of the respondents had primary education, $4.3 \%$ were illiterate and $55.3 \%$ of them were married. (Table 1)

The most commonly perceived occupational hazard was sharp metals $(81.5 \%)$ followed by electric current $(69.7 \%)$.

Regarding the history of occupation, $45.8 \%$ of the respondents worked in the mechanic field for less than five years while $36.5 \%$ had been working for more than eleven years. More than half $(55.5 \%)$ of the mechanics had been working for more than 8 hours a day. More than one-third of them had the habit of alcohol consumption. (Table 2)

Age category, educational status, working hours, years of employment, pre-service training were found to have an association with knowledge on the hazard (p-value $<0.05$ ) whereas there was no association 
seen between sex and knowledge on hazards ( $p$-value $>0.05$ ). Those variables found to have an association with knowledge on hazards were further analyzed and the odds ratio was calculated. The mechanics of age group 30-40 years were found to have good knowledge of hazards. They were found 3.778 times more likely to have adequate knowledge on hazards compared to mechanics of age group 10-20 years. Mechanics having a university level of education were three times more likely to have adequate knowledge on hazards compared to illiterate mechanics. Working hours were statistically significant with awareness of hazards $(p<0.05)$ with crude odds ratio $0.546(95 \% \mathrm{Cl}$ : $0.356,0.837)$. Mechanics working for more than 11 years had twice adequate knowledge on hazards than those working for less than 5 years. Trained mechanics were found to have more knowledge on the hazard in comparison to untrained mechanics with an odds ratio of 1.589 (95\% Cl: 1.038, 2.434). (Table 3)

Knowledge on PPE was found to have an association with age category, education, working hours and pre-service training ( $p$-value $<0.05)$. There was no association found between knowledge on PPE with sex and years of employment ( $p$-value $>0.05$ ). Those variables found to have association were further analyzed and the odds ratio was calculated. A higher level of knowledge on PPE was found in the age group 20-30 years. They had 3.784 times more adequate knowledge on PPE compared to the mechanic of age-group 10-20 years. Mechanics with a secondary level of education were 8.3 times more likely to have adequate knowledge of PPE compared to illiterate mechanics. Working hours were statistically significant with knowledge on PPE $(p<0.05)$ with crude odds ratio 0.333 at $95 \% \mathrm{Cl}$ between $0.215-0.516$. Mechanics receiving pre-service training had twice more adequate knowledge on PPE than those who did not receive training (Table 4).

More than half $(55.5 \%)$ of the workers had sustained various forms of physical injuries in the past one year.
The cut was the most common (44.5\%) form of injuries reported by respondents. Over one-third (38\%) of the mechanics reported any form of physical illness in the past one year. Muscular aches were the most common $(23.8 \%)$ illness followed by headache $(14.8 \%)$ and cough (5\%). (Table 5)

Among the respondents over two-thirds (68.5\%) knew first aid while three-fourths $(75 \%)$ of them had access to first aid in their workplace however only $7.5 \%$ of the workers received training on first aid administration.

More than half of mechanics $(55.5 \%)$ had not received pre-service training. More than one-third (36.8\%) of them had insurance schemes while the majority $(94.5 \%)$ of them had provision of disability leave. More than half $(53.5 \%)$ of the respondents used safety equipment while mask and safety shoes were the most common types of equipment. (Table 6)

On observation of the working environment, it was revealed that only $17.5 \%$ of the garage had the good working environmental condition but most (98.5\%) of them had dry/slip resistance floor. Proper waste management was found in only $18.3 \%$ of garages. However, working areas having adequate illumination and adequate ventilation were $94.8 \%$ and $95.5 \%$ respectively.

Despite being exposed to lots of hazards in the working area only half $(53.5 \%)$ of the workers were found using PPE during their work. The most used PPE was mask $(76.3 \%)$ followed by safety shoes $(61.4 \%)$, gloves (54\%), protective clothing $(49.3 \%)$, while only $28.8 \%$ used safety glasses however the condition of PPE was found to be poor in more than half $(56.8 \%)$ of the respondents.

Age, educational status, working hours, duration of employment and pre-service training was found to have an association with the use of PPE ( $p$-value<0.05), while the sex of the mechanics was found to have no association with knowledge on PPE ( $p$-value>0.05). 
Table 1: Sociodemographic characteristics of the respondents

\begin{tabular}{|c|c|c|}
\hline Characteristics & Frequency & Percentage \\
\hline \multicolumn{3}{|c|}{ Age in years (Mean \pm SD $=28.62 \pm 10.26)$} \\
\hline$<20$ & 109 & 27.2 \\
\hline $20-30$ & 143 & 35.8 \\
\hline $30-40$ & 90 & 22.5 \\
\hline $40-50$ & 50 & 12.5 \\
\hline$\geq 50$ & 8 & 2.0 \\
\hline \multicolumn{3}{|l|}{ Religion } \\
\hline Hindu & 306 & 76.5 \\
\hline Buddhist & 33 & 8.2 \\
\hline Christian & 12 & 3.0 \\
\hline Kirat & 41 & 10.3 \\
\hline Muslim & 8 & 2.0 \\
\hline \multicolumn{3}{|l|}{ Ethnicity } \\
\hline Brahmin/ Chhetri & 97 & 24.2 \\
\hline Janajati & 139 & 34.7 \\
\hline Dalit & 17 & 4.3 \\
\hline Terai/Madhesi & 104 & 26.0 \\
\hline Others & 43 & 10.8 \\
\hline \multicolumn{3}{|c|}{ Educational Status } \\
\hline Illiterate & 17 & 4.2 \\
\hline Literate & 42 & 10.5 \\
\hline Primary & 226 & 56.5 \\
\hline Secondary & 107 & 26.8 \\
\hline University & 8 & 2.0 \\
\hline
\end{tabular}

Table 2: Occupational history and habit of the substance abuse of the respondents

\begin{tabular}{lcc}
\hline Occupational History & Frequency $(\mathbf{n}=\mathbf{4 0 0})$ & Percentage \\
\hline Duration of employment & & \\
$<5$ years & 183 & 45.8 \\
$6-10$ years & 71 & 17.7 \\
$>11$ years & 146 & 36.5 \\
Hours of working per day & & \\
$<8$ hours & 178 & 44.5 \\
$>8$ hours & 222 & 55.5 \\
Substance abuse & Frequency $(\mathbf{n}=\mathbf{2 7 1})$ & Percentage \\
Alcohol & 100 & 36.9 \\
Smoking & 85 & 31.4 \\
Tobacco & 63 & 23.2 \\
Others & 23 & 8.5 \\
\hline
\end{tabular}


Rabina K et al.

Table 3: Association of different characteristics with Knowledge on Health Hazards

\begin{tabular}{|c|c|c|c|c|c|}
\hline \multirow{4}{*}{ Factors } & \multicolumn{4}{|c|}{ Knowledge on types of occupational Health } & \multirow{4}{*}{$\begin{array}{c}95 \% \mathrm{Cl} \\
\text { (Lower-Upper) }\end{array}$} \\
\hline & \multicolumn{2}{|c|}{ Hazards } & \multirow{3}{*}{ p-value } & \multirow{3}{*}{ OR } & \\
\hline & Adequate & Inadequate & & & \\
\hline & $124(31 \%)$ & $276(69 \%)$ & & & \\
\hline \multicolumn{6}{|c|}{ Age in years } \\
\hline $10-20$ & $17(13.7)$ & $92(33.3)$ & 0.003 & Ref. & \\
\hline $20-30$ & $50(40.3)$ & $93(33.6)$ & .001 & 2.910 & $1.563-5.414$ \\
\hline $30-40$ & $37(29.8)$ & $53(19.2)$ & .000 & 3.778 & $1.940-7.356$ \\
\hline $40-50$ & $19(15.3)$ & $31(11.2)$ & .002 & 3.317 & $1.535-7.168$ \\
\hline$\geq 50$ & $1(0.8)$ & $7(2.5)$ & .944 & 1.082 & $.119-9.852$ \\
\hline \multicolumn{6}{|l|}{ Education } \\
\hline Illiterate & $6(4.8)$ & $11(3.9)$ & 0.027 & Ref. & \\
\hline Literate & $9(7.2)$ & $33(11.5)$ & .272 & .500 & $.145-1.724$ \\
\hline Primary & $61(49.2)$ & $165(59.7)$ & .462 & .678 & $.240-1.912$ \\
\hline Secondary & $43(34.6)$ & $64(23.1)$ & .702 & 1.232 & $.424-3.581$ \\
\hline University & $5(4.03)$ & $3(1.08)$ & .209 & 3.056 & $.535-17.462$ \\
\hline \multicolumn{6}{|c|}{ Working hours } \\
\hline$<8$ hours & $68(54.8)$ & $110(39.8)$ & \multirow{2}{*}{0.006} & \multirow{2}{*}{0.546} & \multirow{2}{*}{$0.356-0.837$} \\
\hline$>8$ hours & $56(45.16)$ & $166(60.1)$ & & & \\
\hline \multicolumn{6}{|c|}{ Years of employment } \\
\hline$<5$ years & $44(35.4)$ & $139(50.3)$ & 0.022 & Ref. & \\
\hline $6-10$ years & $25(20.2)$ & $46 \quad(16.6)$ & 0.074 & 1.717 & $.949-3.108$ \\
\hline$>11$ years & $55(44.3)$ & 91 (32.9) & 0.008 & 1.909 & $1.186-3.075$ \\
\hline \multicolumn{6}{|l|}{ Training } \\
\hline No & $59(47.5)$ & $163(59)$ & \multirow{2}{*}{0.033} & \multirow{2}{*}{1.589} & \multirow{2}{*}{$1.038-2.434$} \\
\hline Yes & $65(52.4)$ & $113(40.9)$ & & & \\
\hline
\end{tabular}

Table 4: Association of different characteristics with knowledge of PPE

\begin{tabular}{|c|c|c|c|c|c|}
\hline \multirow[b]{2}{*}{ Factors } & \multicolumn{2}{|c|}{ Knowledge on PPE } & \multirow[b]{2}{*}{ p-value } & \multirow[b]{2}{*}{ OR } & \multirow{2}{*}{$\begin{array}{c}95 \% \mathrm{Cl} \\
\text { (Lower-Upper) }\end{array}$} \\
\hline & $\begin{array}{c}\text { Adequate (\%) } \\
254(63.5)\end{array}$ & $\begin{array}{c}\text { Inadequate (\%) } \\
146(36.5)\end{array}$ & & & \\
\hline \multicolumn{6}{|c|}{ Age in years } \\
\hline $10-20$ & $46(18.1)$ & $63(43.2)$ & 0.000 & Ref. & \\
\hline $20-30$ & $105(41.3)$ & $38(26)$ & 0.000 & 3.784 & $2.225-6.437$ \\
\hline $30-40$ & $64(25.2)$ & $26(17.8)$ & 0.000 & 3.371 & $1.862-6.103$ \\
\hline $40-50$ & $32(12.6)$ & $18(12.3)$ & 0.012 & 2.435 & $1.220-4.861$ \\
\hline$\geq 50$ & $7(2.8)$ & $1(0.7)$ & 0.999 & 1.370 & $.083-22.471$ \\
\hline \multicolumn{6}{|l|}{ Education } \\
\hline Illiterate & $5(1.9)$ & $12(8.2)$ & 0.000 & Ref. & \\
\hline Literate & $19(7.5)$ & $23(15.8)$ & 0.267 & 1.983 & $0.593-6.631$ \\
\hline Primary & $140(55.1)$ & $86(58.9)$ & 0.013 & 3.907 & $1.330-11.473$ \\
\hline Secondary & $83(32.7)$ & $24(16.4)$ & 0.000 & 8.300 & $2.66-25.897$ \\
\hline University & $7(2.8)$ & $1(0.7)$ & 0.018 & 16.80 & $1.617-174.59$ \\
\hline \multicolumn{6}{|c|}{ Working hours } \\
\hline$<8$ hours & 137 (53.9) & $41(28.1)$ & \multirow{2}{*}{0.000} & \multirow{2}{*}{0.333} & \multirow{2}{*}{$0.215-0.516$} \\
\hline$>8$ hours & 117 (46.1) & 105 (71.9) & & & \\
\hline \multicolumn{6}{|c|}{ Pre-service Training } \\
\hline No & $126(49.6)$ & $96(65.7)$ & \multirow{2}{*}{0.002} & \multirow{2}{*}{1.950} & \multirow{2}{*}{$1.280-2.972$} \\
\hline Yes & $128(50.4)$ & $50(34.2)$ & & & \\
\hline
\end{tabular}


Table 5: Incidence of injury and illness among auto mechanics

\begin{tabular}{|c|c|c|c|}
\hline \multicolumn{2}{|l|}{ Characteristics } & \multirow{2}{*}{$\begin{array}{c}\text { Number of mechanics }(n=400) \\
178\end{array}$} & \multirow{2}{*}{$\begin{array}{c}\text { Percentage } \\
44.5\end{array}$} \\
\hline Iniurioc within ovor & No & & \\
\hline Injurles witnin a year & Yes & 222 & 55.5 \\
\hline \multirow{4}{*}{ Among yes injuries* } & Abrasion & 22 & 9.9 \\
\hline & Laceration & 12 & 5.4 \\
\hline & Cut & 178 & 80.2 \\
\hline & $\begin{array}{l}\text { Injured by sharp flying metal } \\
\text { particles }\end{array}$ & 48 & 21.6 \\
\hline \multirow{2}{*}{ Illness } & No & 248 & 62 \\
\hline & Yes & 152 & 38 \\
\hline \multirow{8}{*}{ Among Yes illness* } & Muscular aches & 95 & 68.8 \\
\hline & Headache & 59 & 38.8 \\
\hline & Dizziness & 2 & 1.3 \\
\hline & Cough & 20 & 13.2 \\
\hline & Painful eyes/Eye injuries & 12 & 7.9 \\
\hline & Skin injuries/Skin diseases & 4 & 2.6 \\
\hline & GI problems & 2 & 1.3 \\
\hline & Others & 1 & 0.6 \\
\hline
\end{tabular}

*Multiple responses recorded

Table 6: Availability of benefits and use of safety equipment among auto-mechanics

\begin{tabular}{|c|c|c|c|}
\hline \multicolumn{2}{|c|}{ Facilities and care provision } & \multirow{2}{*}{$\begin{array}{c}\text { Number of mechanics }(n=400) \\
178\end{array}$} & \multirow{2}{*}{$\begin{array}{c}\text { Percentage } \\
44.5\end{array}$} \\
\hline Pre_corvice training & Yes & & \\
\hline rre-service traming & No & 222 & 55.5 \\
\hline \multirow{2}{*}{ Life insurance schemes } & Yes & 147 & 36.8 \\
\hline & No & 253 & 63.3 \\
\hline \multirow{2}{*}{ Disability leave } & Yes & 378 & 94.5 \\
\hline & No & 22 & 5.5 \\
\hline \multirow{2}{*}{ Use of safety equipment } & Yes & 214 & 53.5 \\
\hline & No & 186 & 46.5 \\
\hline \multirow{7}{*}{ Type of safety equipment* } & Safety glasses & 62 & 28.8 \\
\hline & Gloves & 114 & 54.0 \\
\hline & Mask & 162 & 76.3 \\
\hline & Ear plugs & 5 & 2.3 \\
\hline & Safety shoes & 132 & 61.4 \\
\hline & Face shields/Helmets & 36 & 16.7 \\
\hline & Protective clothing & 106 & 49.3 \\
\hline
\end{tabular}

${ }^{*}$ Multiple responses recorded

\section{Discussion}

About one-third (36\%) of the mechanic in this study were in the category (20-30 years) which is similar to the study among mechanic in North-Western Nigeria where a higher proportion (31\%) of mechanic were between the age group 20-29 years in contrast with the study where a majority $(36 \%)$ of the workers were of age group 26-35 years., ${ }^{7,8}$ Very few $(0.5 \%)$ female mechanics were found in this study, which is similar toa study among automobile technicians at the mechanic village, Uyo, Nigeria where only $2 \%$ of mechanics were females. ${ }^{9}$ It shows females are rarely engaged in vehicle repairs. It confirms young and energetic males dominate this kind of work, which might be due to the laborious nature of the work.

Only $4.3 \%$ of mechanics in this study were illiterate, which is similar to the study done among 330 welders in Nigeria where only $7.6 \%$ of the respondents were 
illiterate. ${ }^{10} \mathrm{Although}$ a majority $(85 \%)$ of the mechanic had primary or higher-level education, only $31 \%$ had adequate knowledge on the hazard and only $63.5 \%$ had adequate knowledge on PPE. This reflects that occupational health is not getting adequate emphasis.

More than a half $(56 \%)$ of the mechanics were working for more than 8 hours a day differing from a study done among factory workers in Nigeria where only onefourth $(23.72 \%)$ of the respondents were working for more than 8 hours a day. ${ }^{11}$ This must be as a need to earn enough money for the family as more than half of the mechanics in this study were married.

The automobile repairing profession is full of hazards and very few mechanics know about it. In this study, less than one-third $(31 \%)$ of mechanics had adequate knowledge of hazards of automobiles repairing, which differs from the study conducted in Eastern Nepal where a majority $(90 \%)$ of the welders were aware of the hazards. ${ }^{3}$ The common hazards known to the respondents were sharp metals $(15.4 \%)$, followed by electric current $(13.1 \%)$, metal fumes $(12.6 \%)$ and so on. It varies from a study done on automobile artisans in Kathmandu where chemicals were most common (14.1\%) followed by heat (13.8\%). ${ }^{6}$ The knowledge on hazards showed significant association with age, educational status, working hours, years of employment and pre-service training which was similar to the study done among 330 welders in Nigeria. ${ }^{12}$

Among the age groups, the 30-40 years group were found to have the greatest knowledge on hazards. They were found to have four times more adequate knowledge on hazard compared to mechanics of age group ( $<20$ years). Those workers who attained university-level education were found to have three times more knowledge on hazard compared to illiterate workers similar to a study where welders with primary education were seven times more likely to be aware of hazards than illiterate welders. ${ }^{3}$ Muscular aches were found to be the most common (23.8\%) illness followed by headache $(14.8 \%)$ corresponding with the study done among workers in Zaria, Ghana and study done among welders in Nigeria where the musculoskeletal disease was found to be the most common illness. ${ }^{7,8}$ The work requires physical exertion and due to improper postures of workers, while working, a high prevalence of muscular aches is to be expected. Working under vehicles, using heavy machinery and tool for several hours make auto mechanics prone to musculoskeletal problems. The cut was identified to be the chief cause of injury with correspondence with the study in automobile repair workers. ${ }^{13}$ This may be due to the nature of their work involved in handling metal parts, which could easily lead to injuries.

Access to first aid among workers was very high (75\%) contrary to a study done in automobile artisans in Kathmandu where only one-third $(33 \%)$ had facilities of first aid while another study in Nigeria where only $8 \%$ had access to first aid. ${ }^{6,8}$ Very few $(7.5 \%)$ mechanic received training on first aid, which is similar to study done in an urban area of South India which was only $10 \% .{ }^{14}$ The self-medication after injury was found to be $35.5 \%$, which was less compared to the study done in Nigeria where $78.95 \%$ were found using selfmedication but still this may impose health effect as indicated by various research. ${ }^{15},{ }^{16}$ Less than half $(45 \%)$ of the mechanics received pre-service training before work, which shows a similar result with the study done among automobile repair workshops in Ghana where $40 \%$ received pre-service training. ${ }^{17}$ Lack of cleanliness increases the risk of mechanics towards various infectious diseases. On observation of the working environment, only $17.5 \%$ of the environment of the workshop was in good condition contrary to the local automotive garage in Ghana where $59.4 \%$ of the workshop was clean. ${ }^{18}$

Although $63.5 \%$ of the mechanic had adequate knowledge of PPE only $53.5 \%$ were found to use them. This difference might be due to the carelessness of worker or uneasiness on performing work due to its use. A similar practice was found in a study among industrial workers in Nawalparasi where only $68.1 \%$ were found to use PPE. ${ }^{19} \mathrm{~A}$ difference in knowledge and use of PPE was seen with the welders of Nigeria where only $36 \%$ were found to use PPE. ${ }^{20}$

The use of PPE was associated with age, educational status, working hours, duration of employment and preservice training. There was no association of the use of PPE with sex, which differs from the study done on industrial workers in Nawalparasi. ${ }^{19}$ In a study done by Budathoki et al., education and duration of employment were found to be associated with awareness of hazards, PPE and its use, which is similar to our study. ${ }^{3}$

20-30 years of age group were found to have the greatest knowledge on PPE. They had four times more knowledge than 10-20 years mechanic. Those workers having university-level education were found to have 16 times more knowledge on PPE than illiterate. 
There was a significant association between knowledge on the hazard $(p<0.05)$ and knowledge on PPE $(p<0.05)$ with the use of PPE, which is similar to the study done among mechanics in Kathmandu metropolitan city. ${ }^{6}$ Thus, education and training seems more effective for the practice of using PPE.

\section{Conclusion}

Education and training seem to have an effective role in the use of PPE. The majority of workers were literate and from a younger age group. Very few workers had adequate knowledge of hazards. Also, knowledge of PPE was not very good. Strict rules and regulations on the use of PPE must be implemented and regular monitoring should be conducted.

\section{Acknowledgement}

We would like to acknowledge all the participants of the study as well as express our sincere thanks to all the faculties of the Department of Public Health, Manmohan Memorial Institute of Health Sciences.

\section{References}

1. Alli B. Fundamental principles of occupational health and safety (Internet). Geneva: International Labour Office; 2008.Available from: https://www.ilo.org/ wcmsp5/groups/public/@dgreports/@dcomm/@ publ/documents/publication/wcms_093550.pdf

2. Gautam RP, Prasain JN. Current situation of occupational safety and health in Nepal. General Federation of Nepalese Trade Unions (GEFONT) Man Mohan Labour Building, GEFONT Plaza, Putalisadak, Kathmandu, Nepal. 2011.

3. Budhathoki SS, Singh SB, Sagtani RA, Niraula SR, Pokharel PK. Awareness of occupational hazards and use of safety measures among welders: a crosssectional study from eastern Nepal. BMJ open. 2014;4(6):004646.Available from:https://www.ncbi. nlm.nih.gov/pmc/articles/PMC4054643/

4. Shweta S. Development of suitable functional clothing for workers of cement industry (Internet). 2018. Avaiable from: https://www.semanticscholar. org/paper/DEVELOPMENT-OF-SUITABLEFUNCTIONAL-CLOTHING-FOR-OFShweta/3056a 2199d12381b4cd8bbd6d0ff5e8b0219879d\#paperheader

5. Lund F, Marriott A. Occupational health and safety and the poorest (Internet). South Africa: School of Development Studies, University of KwaZulu-Natal; 2011. Avaiable from: http://sds.ukzn.ac.za/files/ RR\%2088\%20Lund.pdf

6. Marahatta SB, Gautam S, Paudel G, Yadav UN. Awareness of occupational hazards and associated factors among automobile repair artisans in Kathmandu Metropolitan City, Nepal. Indian journal of occupational and environmental medicine. 2018;22(1):49

7. Sambo M, Idris S, Shamang A. Determinants of occupational health hazards among roadside automobile mechanics in Zaria, North Western Nigeria. Borno Medical Journal. 2012;9(1):5-9.

8. Monney I, Bismark D-A, Isaac O-M, Kuffour RA. practices among vehicle repair artisans in an urban

area in Ghana. J Environ Occup Sci, Apr-Jun. 2014;3(3):147-53.

9. Johnson OE, Bassey EA. Work habits and health problems of automobile technicians at mechanic village, Uyo, Nigeria. Global Adv Res J Med Sci. 2016;5:136-42.

10. Sabitu K, lliyasu Z, Dauda M. Awareness of occupational hazards and utilization of safety measures among welders in Kaduna metropolis, Northern Nigeria. Annals of African Medicine. 2009;8(1):46.

11. Oranusi S, Dahunsi S, Idowu S. Assessment of occupational diseases among artisans and factory workers in Ifo, Nigeria. Journal of Scientific Research \& Reports. 2013;3(2):294-305

12. Awoyemi A. Awareness about occupational hazards among roadsides automechanics in Ilorin, Nigeria. Journal of Community Medicine \& Primary Health Care. 2002;14:27-33.

13. Vyas H, Das S, Mehta S. Occupational injuries in automobile repair workers. Industrial health.2011:1108050094.Available from: https://www. jstage.jst.go.jp/article/indhealth/49/5/49_MS1294/_ article

14. Kumar SG, Dharanipriya A, Kar S. Awareness of occupational injuries and utilization of safety measures among welders in coastal South India. Int J Occup Environ Med (The IJOEM). 2013;4(4 October):172-7.

15. Lawan UM, Abubakar IS, Jibo AM, Rufai A. Pattern, awareness and perceptions of health hazards associated with self medication among adult residents of kano metropolis, northwestern Nigeria. Indian journal of community medicine: official publication of Indian Association of Preventive \& Social Medicine. 2013;38(3):144.

16. Afolabi A. Factors influencing the pattern of selfmedication in an adult Nigerian population. Annals of African medicine. 2008;7(3):120-7.

17. Akple MS, Turkson RF, Biscoff R, Nyamuame GY. Accident and safety violation in automobile 
repair workshops in Ghana. International Journal of Business, Management and Social Sciences. 2013;4(1):12-21.

18. Apreko AA, Danku LS, Apeletey MSAAF. Occupational Health and Safety Management: The Use of Personal Protective Equipment (Ppe) by Artisans in The Local Automotive Industry in Volta Region, Ghana. Ghana Int J Eng Trends Tech. 2015;19:201-5.
19. Acharya SR. Utilization pattern of personal protective equipment among industrial workers of Nawalparasi, Nepal. Health Prospect. 2014;13(2):24-7.

20. Isah E, Okojie O. Occupational health problems of welders in Benin City, Nigeria. Journal of Medicine and Biomedical Research. 2006;5(1):64-9. 